\title{
Expression Profiling Reveals Involvement of WNT Pathway in the Malignant Progression of Sessile Serrated Adenomas
}

\author{
Mahra Nourbakhsh, ${ }^{* \dagger}$ Adnan Mansoor, ${ }^{* \dagger}$ Konstantin Koro, ${ }^{* \dagger}$ Qingrun Zhang, ${ }^{\dagger}$ and Parham Minoo ${ }^{* \dagger}$
}

From the Department of Pathology, * Cumming School of Medicine and Alberta Public Laboratories, and the Department of Biochemistry and Molecular Biology, ${ }^{\dagger}$ University of Calgary, Calgary, Alberta, Canada

Accepted for publication

May 7, 2019.

Address correspondence to Parham Minoo, M.D., Ph.D., Department of Pathology, Cumming School of Medicine, University of Calgary, and Alberta Public Laboratories, Foothills Medical Centre, McCaig Tower, Room 7563, 1403-29th St. NW, Calgary, AB T2N 2T9, Canada. E-mail: parham.minoo@cls.ab.ca.

\begin{abstract}
Approximately $15 \%$ to $20 \%$ of colorectal cancers are developed through the serrated pathway of tumorigenesis, which is associated with BRAF mutation, CpG island methylation phenotype, and MLH1 methylation. However, the detailed process of progression from sessile serrated adenoma (SSA) to dysplasia and carcinoma has not been elucidated. To further characterize mechanisms involved in the dysplastic progression of SSA, we investigated differential expressions of mRNAs between areas with and without dysplasia within the same SSA polyps. Significantly dysregulated genes in paired samples were applied for functional annotation and biological significance. The same lysates from a subset of matched samples were subjected for miRNA expression profiling. Differentially expressed miRNAs were determined, and their targeted mRNAs were compared in parallel to the list of differentially expressed mRNAs from an RNA sequencing study. Fourteen common mRNA targets were identified, which include AXIN2, a known indicator of WNT/ $\beta$-catenin pathway activation. Together, in this study, different genes, pathways, and biological processes involved in the initiation and progression of dysplasia in the serrated pathway are documented. One of the most significant findings is the involvement of the WNT/ $\beta$-catenin pathway in the dysplastic progression of SSAs with different genes being targeted in early versus advanced dysplasia. (Am J Pathol 2019, 189: 1732-1743; https://doi.org/10.1016/j.ajpath.2019.05.009)
\end{abstract}

Colorectal cancer (CRC) is the third most common malignant tumor and the fourth leading cause of cancer death worldwide. ${ }^{1}$ For many years, the conventional adenoma to carcinoma sequence was known as the only route for colorectal carcinogenesis. However, emerging evidence indicates an alternative pathway of colorectal tumorigenesis, namely the serrated pathway, which accounts for approximately $15 \%$ to $20 \%$ of CRCs. Sessile serrated adenoma (SSA) represents a major precursor for the serrated pathway of CRC and accounts for almost $25 \%$ of all colorectal serrated lesions. $^{2-4}$ Compared with the conventional pathway of colorectal tumorigenesis, the sequence of molecular events in the serrated pathway is less understood. Most early serrated lesions develop through $B R A F$ (or to a lesser extent $K R A S$ ) mutations and $\mathrm{CpG}$ island methylation within the promoter region of multiple genes, a process that leads to CpG-island methylator phenotype (CIMP) and silencing of numerous tumor-related genes. ${ }^{5-7}$ CIMP can be found in most SSAs and sporadic microsatellite instabilityhigh (MSI-H) CRC cases, although it is not restricted to these groups. $^{8-11}$ In a subset of the CIMP-positive serrated lesions, hypermethylation of $\mathrm{CpG}$ islands located in the promoter region of $M L H 1$ gene leads to mismatch repair deficiency and consequently microsatellite instability. Although the contribution of BRAF mutation, CIMP phenotype, and $M L H 1$ methylation in the development of sporadic MSI-H CRCs is well documented, the detailed process of progression from SSA to dysplasia and carcinoma remains elusive.

To investigate the mechanisms involved in the dysplastic progression of SSAs, the differential expressions of mRNAs

Supported by Calgary Laboratory Services (currently Alberta Public Laboratories) research grants RS14-518 (P.M.), RS14-520 (P.M.), RS14527 (P.M.), and RS15-500 (P.M.).

Disclosures: None declared. 
and miRNAs in the regions of SSA and SSA with morphologic dysplasia were evaluated within the same polyp. The following challenges exist in assessing the expression profile of dysplastic SSAs: i) morphologic features are required for the diagnosis of dysplasia and therefore fresh tissue cannot be used; ii) areas of dysplasia in SSAs are typically small and yielded genomic material is often low; and iii) quality of RNA is suboptimal in formalinfixed, paraffin-embedded (FFPE) tissue. A novel sensitive method for RNA sequencing, namely AmpliSeq transcriptome analysis, with optimized efficiency for detection of small amounts of RNA in FFPE tissue was used. ${ }^{12,13}$ For miRNA evaluation, a nanostring platform was used, which contained adequate probes to cover the most important target miRNAs (approximately 800 targets) and was previously reported to have superior efficiency in FFPE tissue. ${ }^{14,15}$ Significantly dysregulated genes were applied for functional annotation and biological significance using Ingenuity Pathway Analysis (IPA) software version 01-12 ${ }^{14}$ (Qiagen, Hilden, Germany) and Database for Annotation, Visualization and Integrity Discovery (DAVID) version 6.8 (National Institute of Allergy and Infectious Diseases, NIH, Bethesda, MD; https://david.ncifcrf.gov). In a few prior reports, gene expression profiling of SSA was attempted. ${ }^{16-18}$ However, the focus of these studies was to identify genes involved in the development of SSA and not its dysplastic progression. This study is also unique with respect to side by side comparison of nondysplastic versus dysplastic components in each SSA polyp. Combined analysis of miRNA and mRNA data in parallel for the same individual polyps added more strength to the findings.

\section{Materials and Methods}

\section{Tissue Selection, Inclusion Criteria, and Clinicopathologic Data}

This study was approved by the Ethics Committee of the University of Calgary. A search was made in the University of Calgary database (from 2011 to 2015) for the colon polyps with the diagnosis of SSA with dysplasia, arising from the right side of the colon (cecum, ascending and transverse colon). The polyps were reviewed, and 21 SSA polyps in which dysplasia encompassed more than a single $10 \times$ field $(>2 \mathrm{~mm}$ ) were selected. These polyps include 12 SSA polyps with areas of low-grade dysplasia (SSA-LD group) and 9 SSA polyps that contained areas of high-grade dysplasia (SSA-HD group). In each group (SSA with or without dysplasia), tissue was harvested in the form of 1$\mathrm{mm}$ cores. For the paired control group, tissues were collected from the nondysplastic SSA portion, adjacent but at least one $4 \times$ field $(>5 \mathrm{~mm}$ ) away from the dysplastic area of each polyp (SSA-ND group). This approach was performed to minimize the risk of cross-contamination.

Histologic criteria used for the diagnosis of SSA with dysplasia include i) the presence of SSA component within the lesion, ii) an abrupt transition from SSA to SSA with unequivocal dysplasia, and iii) exclusion of cases with traditional serrated adenoma arising in an SSA. Low-grade conventional dysplasia is defined by narrow, elongated, hyperchromatic, pseudostratified nuclei with basophilic cytoplasm. High-grade dysplasia is defined by significant polymorphism, increased mitotic activity, and loss of polarity and architecture complexity, including cribriforming. Cases with serrated-type dysplasia are excluded. The clinicopathologic data, including age, sex, size, and location of the polyp in the colon, are summarized in Supplemental Table S1. Briefly, SSA-LDs (12 polyps) were excised from six females (50\%) and six males (50\%), whereas SSAHDs (nine polyps) were excised from five females (56\%) and four males (44\%). Of the SSA-LDs (12 polyps), eight $(67 \%)$ were located in the ascending colon, three $(25 \%)$ in the cecum, and one (8\%) in transverse colon. In the SSAHD group (nine polyps), six (67\%) were in the ascending colon, two (22\%) in the cecum, and one (11\%) in the transverse colon. The mean size in SSA-LD group was 1.2 $\mathrm{cm}$, whereas the mean size in the SSA-HD group was 1.3 $\mathrm{cm}$. The mean age of patients in the SSA-LD group was 67.6 years, whereas the mean age was 70.6 years in SSAHD group.

\section{RNA Extraction, Integrity Assessment, mRNA Sequencing, and Data Analysis}

RNA was extracted from formalin-fixed, paraffin-embedded (FFPE) tissue using an Ambion Kit for Nucleic Acid Isolation from FFPE (Thermo Fisher Scientific, Waltham, MA). In summary, duplicate 1-mm cores of tissue from the nondysplastic and dysplastic portions of each polyp were dissected from the FFPE blocks. Samples were deparaffinized with Xylene and washed with alcohol before RNA extraction. The quantity of extracted RNA samples was assessed using Nanodrop UV-VIS spectrophotometer (NanoDrop Technologies, Wilmington, DE), and the integrity of RNA was assessed using a Bio-analyzer 2100 and RNA Nano Chip assay (Agilent Technologies, Wilmington, DE). Whole transcriptome sequencing was outsourced to the nextgeneration sequencing laboratory in Dr. Djavad Mowafaghian Centre for Brain Health at the University of British Columbia and was performed using $100 \mathrm{ng}$ of total RNA with AmpliSeq Transcriptome Human Gene Expression kit on an Ion Proton sequencer (Life Technologies, Carlsbad, CA).

For mRNA sequencing, the Ion Torrent Server version 5.0 (Thermo Fisher Scientific) was used to align the short reads in fastq files to the National Center for Biotechnology Information 37.1 reference genome. The AmpliSeq RNA plugin was used to generate absolute and normalized gene expression values. Genome annotation database and the quantification of the relative abundance of each transcript were reported as fragments per kilobases of transcript per million mapped reads. Qualified samples had a means \pm SD of $10.4 \pm 2.5$ reads. Low-expression genes were filtered out as 
suggested by Sha et al. ${ }^{19}$ Wilcoxon signed-rank test was used to compare matched samples (SSA versus SSA-LD and SSA versus SSA-HD). The $U$ test was used to compare unpaired samples (SSA-LD versus SSA-HD). The BenjaminiHochberg method was used to control the false discovery rate (FDR). The threshold of declaiming a gene to be differentially expressed [differentially expressed genes (DEG)] are based on FDR $\leq 0.05$ and $\log _{2}$ fold change (FC) absolute value $>1.5$. For cluster analysis, expression data were first scaled by SD for each gene. Euclidean distance was used for dissimilarity measure. Unsupervised, nonhierarchical clustering using the K-mean method was then applied.

For functional annotation and biological significance, the DEGs were analyzed with the IPA software. In addition, gene ontology analysis was also performed on the DEGs using the DAVID. FDR $\leq 0.05$ was used as the criteria for gene ontology category enrichment. RNA sequencing data have been deposited in the ArrayExpress database (European Molecular Biology Laboratory-European Bioinformatics Institute, Cambridge, UK; https://www.ebi.ac.uklarrayexpress/ experiments/E-MTAB-7960, last accessed July 2, 2019).

\section{NanoString Code Set Design and miRNA Expression Assay and Data Analysis}

RNA samples extracted from four randomly selected SSAs with low-grade dysplasia and their associated SSAs without dysplasia were processed using an nCounter Human miRNA Expression Assay version 3 kit (NanoString Technologies, Seattle, WA) that contained probes and miTags for 822 important miRNAs related to the major pathways in neoplastic events. Briefly, probes were hybridized to $300 \mathrm{ng}$ of total RNA extracts for 20 hours at $65^{\circ} \mathrm{C}$ and applied to the nCounterTM Prep Station for automated removal of excess probe and immobilization of probe-transcript complexes on a streptavidin-coated cartridge. Data were collected using the nCounterTM Digital Analyzer by counting the individual barcodes.

NanoString data processing was performed using nSolver Analysis Software version 3.0 (NanoString Technologies). Raw miRNA counts were normalized with ligation control. The background level of expression for each sample were calculated by the mean counts of negative control plus two SDs of the mean and were subtracted from the raw data counts of the sample. Normalized data were $\log _{2}$-transformed and then used as input for further analysis.

The $U$ test was used for analysis of statistically significant miRNAs between SSAs with low-grade dysplasia and their nondysplastic counterparts. The threshold of declaiming a miRNA to be differentially expressed are based on $P \leq 0.05$ and $\log _{2} \mathrm{FC}$ absolute value $>1.5$.

SPSS software version 20.0 (IBM, Armonk, NY) was used for statistical evaluation, and Prism version 7.0 software (GraphPad Software Inc., La Jolla, CA) was used for graphing. nSolver software version 3.0 (NanoString Technologies) was used for the normalization of raw counts.
Nonhierarchical clustering, principle component analyses, and volcano plot were performed on R Package Bioconductor ComplexHeatmap Software version 3.7 (Bioconductor, Lund, Sweden), and Qlucore Omics Explorer version 3.2 (Qlucore, Lund, Sweden), and R Graphing Library (Plotly, Montreal, QC, Canada).

\section{Quantitative PCR}

Target and reference miRNA were reverse transcribed using the TaqMan MicroRNA Reverse Transcription Kit (Thermo Fisher Scientific) and the following specific TaqMan miRNA assays: has-miR-222-3p (002276), hsa-miR-191 (002299), and U6 snRNA (001973). Ten nanograms of total RNA was used as input for each reverse transcription reaction. miRNA expression was determined by quantitative PCR on an ABI 7500 Fast instrument (Thermo Fisher Scientific). Each singleplex assay was performed in duplicate, consisting of $1 \mu \mathrm{L}$ of $20 \times$ TaqMan assay, $1.33 \mu \mathrm{L}$ of reverse transcription reaction, $10 \mu \mathrm{L}$ of TaqMan Universal PCR Master Mix $(2 \times)$, and 7.67 $\mu \mathrm{L}$ of nuclease-free water. The following cycling conditions were used: $50^{\circ} \mathrm{C}$ for a 2 -minute hold, $95^{\circ} \mathrm{C}$ for a 10 -minute hold, $95^{\circ} \mathrm{C}$ for 15 seconds, and $60^{\circ} \mathrm{C}$ for 1 minute for 40 cycles. miR-222-3p relative expression levels were calculated using the $\Delta \Delta \mathrm{Ct}$ method and SDS software version 2.05 (Thermo Fisher Scientific). A comparison between the SSA and SSA-LD groups was performed using the $t$-test. Relative expression miR-191 and U6 served as internal reference controls for each assay.

\section{Immunohistochemistry}

Immunohistochemistry stains using anti- $\beta$-catenin antibody (dilution 1:1000, $30 \times 30$, high $\mathrm{pH}$, clone 14 ; $\mathrm{BD}$ Bioscience, Franklin Lakes, NJ) were performed on 4- $\mu \mathrm{m}$ sections of FFPE tissue using a Omnis platform (Dako Cytomation, Glostrup, Denmark). Slides were then counterstained and visualized by light microscopy. Slides were scored by two pathologists independently. Discrepant scores were resolved after joint evaluation of cases. $\beta$-catenin immunostain showed membranous, cytoplasmic, and nuclear staining patterns. The results of staining were considered positive for nuclear accumulation if $>50 \%$ of cells showed nuclear staining in longitudinally oriented crypts. Immunohistochemistry stains were performed on a separate independent cohort of 20 dysplastic SSAs comprising 10 SSA-LDs and 10 SSA-HDs. The original cohort could not be used as in many cases the dysplastic component was exhausted for RNA extraction. Nuclear $\beta$ catenin expression was compared between SSA-LD and SSA-HD using the Fisher exact test.

\section{Methylation-Specific PCR}

DNA was extracted from corresponding lysate material used for RNA extractions following the manufacturer's protocol 
(QIAamp DNA Micro Kit, Qiagen). Five cases of randomly selected SSA-LD and five cases of SSA-HD were included for analysis of AXIN2 promoter methylation. DNA concentration and purity were assessed by NanoDrop 2000c spectrophotometer (Thermo Fisher Scientific). All samples had 260/280-nm absorbance values $>1.9$. For each sample, $1 \mu \mathrm{g}$ of genomic DNA was bisulfite treated using the EpiTect Fast Bisulfite Kit according to the manufacturer's protocol (Qiagen). Samples were eluted in $15 \mu \mathrm{L}$ of elution buffer, and $4 \mu \mathrm{L}$ served as template for each PCR reaction. The following primers pairs were used ${ }^{20}$ : AXIN2 $\mathrm{M}$ forward $5^{\prime}$-ATATAGTTTAGCGGTTGGGAGTGC- $3^{\prime}$ and AXIN2 $M$ reverse 5'-CACTCGACCAAAACGCACG-3' 112 bp; AXIN2 UM forward 5'-ATAGTTTAGTGGTTGGGAGTGT-3' and AXIN2 UM reverse 5'-CCACTCAACCAAAACACACA-3' 113 bp. PCR reactions consisted of $5 \mu \mathrm{L}$ of $10 \times \mathrm{HiFi}$ PCR buffer, $2 \mu \mathrm{L}$ of $50 \mathrm{mmol} / \mathrm{L} \mathrm{MgSO}_{4}$, $1 \mu \mathrm{L}$ of $10 \mathrm{mmol} / \mathrm{L} \mathrm{dNTP} \mathrm{mix,} 1 \mu \mathrm{L} 10 \mu \mathrm{mol} / \mathrm{L}$ forward primer, $1 \mu \mathrm{L} 10 \mu \mathrm{mol} / \mathrm{L}$ reverse primer, and $0.2 \mu \mathrm{L}$ Platinum Taq DNA polymerase HiFi $5 \mathrm{U} / \mu \mathrm{L}$ (Thermo Fisher Scientific). Unmethylated PCR cycling conditions were as follows: $94^{\circ} \mathrm{C} 2$ minutes initial denaturation followed by $94^{\circ} \mathrm{C} 15$ seconds, $56^{\circ} \mathrm{C}$ annealing 30 seconds, and $68^{\circ} \mathrm{C}$ for 30 seconds for 35 cycles followed by 5 minutes o final extension at $68^{\circ} \mathrm{C}$. The same conditions were used for the methylated reaction except annealing temperature was $62^{\circ} \mathrm{C}$. PCR products were visualized on a Bioanalyzer 2100 instrument (Agilent, Santa Clara, CA) using a DNA 1000 assay kit according to manufacturer's protocol. Methylation of AXIN2 promoter was compared between SSA-LD and SSA-HD groups using the Fisher exact test.

\section{Results}

\section{Differentially Expressed Genes in SSA-LD and SSA-HD versus SSA-ND}

To identify the genes that are dysregulated in dysplastic SSAs, 12 SSA-LD and 10 SSA-HD polyps were selected. One SSA-HD failed to show optimal reads and was therefore excluded from the study. The expression levels of mRNA between dysplastic areas of SSA polyps were compared with those in the nondysplastic (SSA-ND) portion of each SSA polyp. To reduce the large sets of data, two exclusion criteria were applied: FDR $\leq 0.05$ and $\log _{2}$ FC absolute value $>1.5$. From 20,812 genes that had abundant expression levels (fragments per kilobases of transcript per million mapped reads $>1$ ) by mRNA sequencing, 114 genes in the SSA-LD group and 153 genes in the SSA-HD group were differentially expressed compared with their nondysplastic counterparts (Supplemental Tables S2 and S3). In the SSA-LD group, these 114 DEGs included 54 up-regulated genes and 60 down-regulated genes (Figure 1A). In the SSA-HD group from 153 DEGs, 103 genes were upregulated, and 50 genes were down-regulated (Figure 1B). Unsupervised, nonhierarchical clustering analysis of the 114
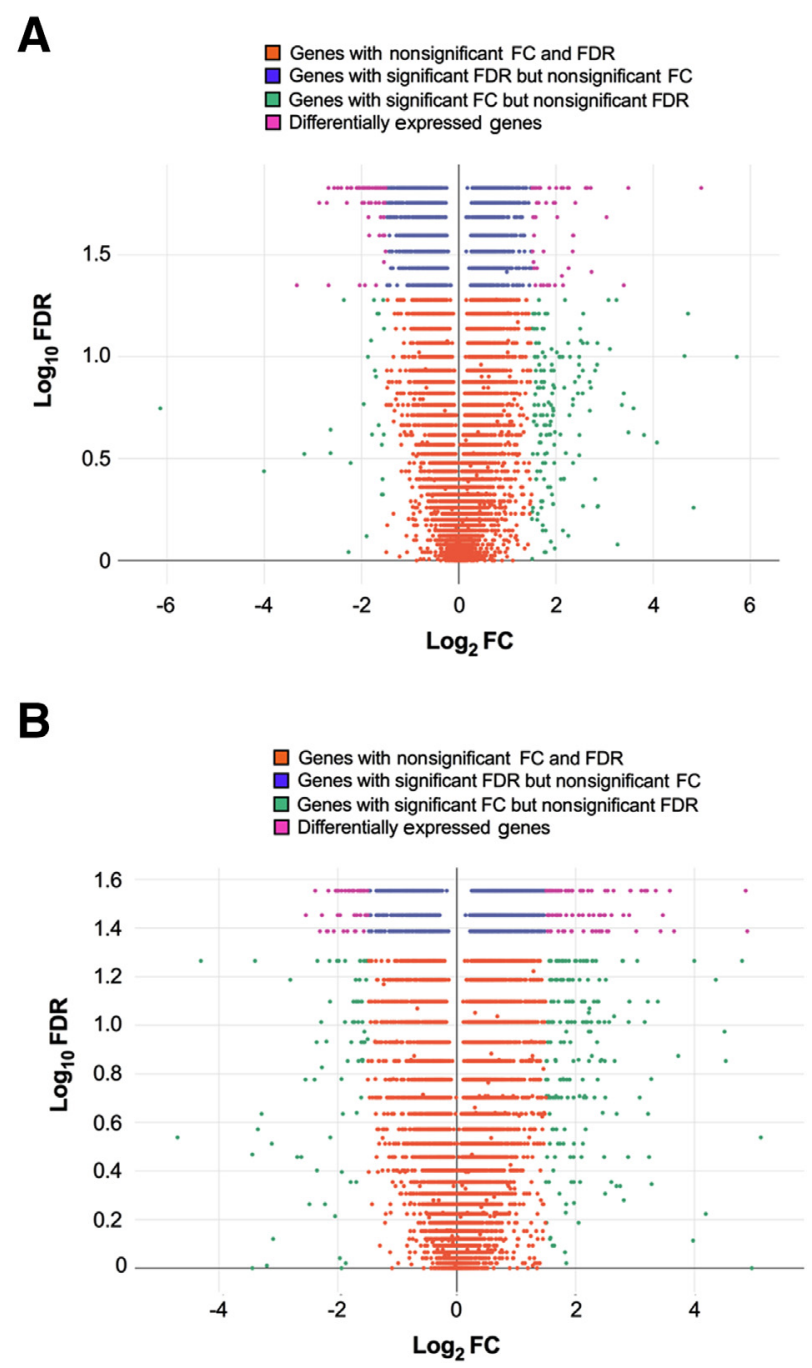

Figure 1 Volcano plot of 20,812 genes in sessile serrated adenoma-low grade (SSA-LD) (A) and sessile serrated adenoma-high grade (SSA-HD) (B) with mean fragments per kilobases of transcript per million mapped reads $>1$ and false discovery rate (FDR) $\leq 0.05$. Each circle corresponds to one gene. The $x$ axis represents the gene $\log _{2}$ [SSA-LD or SSA-HD/SSA-ND (nondysplastic)] fold change (FC) value, and the $y$ axis represents the $\log _{10}$ FDR value calculated from the Wilcoxon signed-rank test and Benjamini-Hochberg method between dysplastic portion of polyps and its nondysplastic counterpart. The pink circles represent the differentially expressed genes with the gene $\log _{2}$ value $>1.5$ or $<-1.5$ and the $\log _{10}$ FDR value $\leq 0.05$. The purple, green, and orange circles represent the genes with $\log _{2} \mathrm{FC}$ values between -1.5 and 1.5 or $\log _{10} \mathrm{FDR}$ values $>0.05$ or both.

DEGs in the SSA-LD group and 153 DEGs in the SSA-HD group found that 12 of 12 SSA-LD samples and six of nine SSA-HD samples were clustered into distinct groups separated from their SSA counterparts in another group (Figure 2). These data demonstrate that SSA-LD and SSAHD can generally, but not in every case, be distinguished from their adjacent nondysplastic components using largescale gene expression analysis. Although the presence of occasional outliers in SSA-HD may represent alternative pathways involved in dysplasia in these polyps, the 


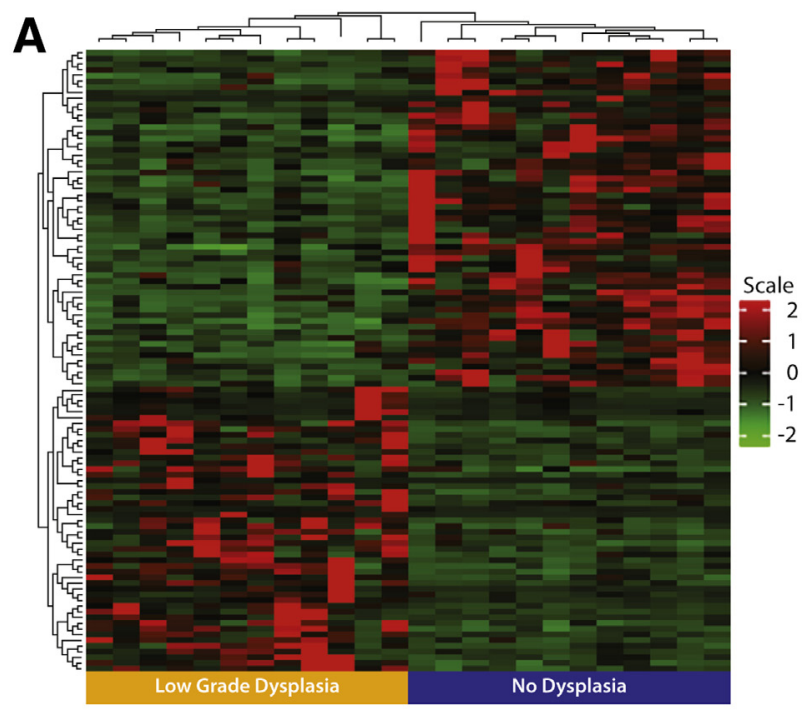

B

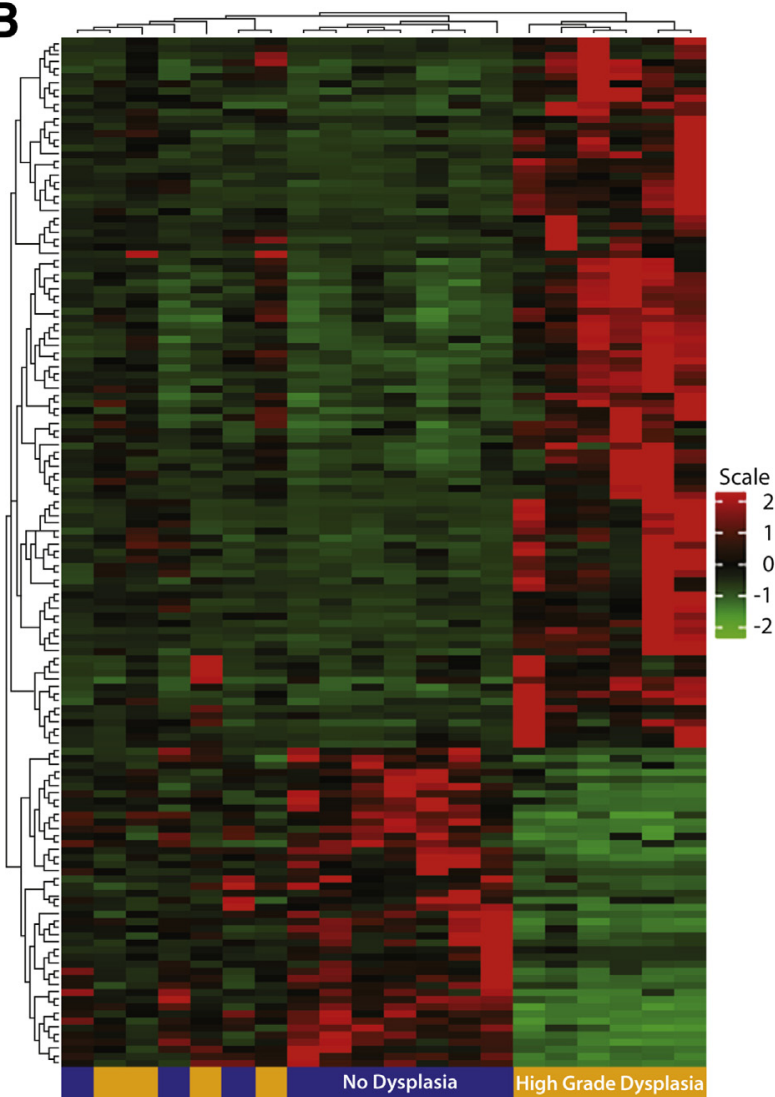

Figure 2 Nonhierarchical clustering analysis of 114 differentially expressed genes (DEGs) in sessile serrated adenoma-low grade (SSA-LD) (A) and 153 DEGs in sessile serrated adenoma-high grade (SSA-HD) (B) compared with no dysplasia (SSA-ND).

possibility of nonpreferred quality of RNA in FFPE samples as a contributing factor cannot be excluded. Unpaired comparison was performed between the SSA-LD and SSAHD groups. This comparison revealed three genes with significant differential expression, namely LGALS1 (which express galectin-1), Spock1, and TGFB2.
Biological Processes Involved in Progression of SSA to SSA-LD

Analysis of the 114 differentially expressed genes in SSA with low-grade dysplasia found significant alterations in $15 \mathrm{key}$ biological processes as defined by DAVID Bioinformatics and IPA. Nine of these biological processes were significantly upregulated in SSA-LD, and six processes were down-regulated (Figure 3A). The up-regulated processes included cellular response to carbohydrate stimulus, positive regulation of glycolytic process, positive regulation of telomerase activity, regulation of calcium ion-dependent exocytosis, response to lipopolysaccharides, WNT signaling pathway, inflammatory response, immune response, and G-protein-coupled receptor signaling pathway. The down-regulated processes included negative regulation of cytokine production involved in inflammatory response, positive regulation of guanylate cyclase activity, cellular response to fluid shear stress, maintenance of gastrointestinal epithelium, brown fat cell differentiation, and regulation of intracellular $\mathrm{pH}$. Enrichment of several canonical pathways were also highlighted by the pathway analysis (Supplemental Figure S1A), such as WNT/ $\beta$-catenin signaling $\left(P=1.51 \times 10^{-3}\right)$, granulocyte adhesion and diapedesis $\left(P=1.8 \times 10^{-3}\right), \mathrm{LXR} / \mathrm{RXR}$ activation $\left(P=2.86 \times 10^{-3}\right)$, agranulocyte adhesion and diapedesis $\left(P=1.40 \times 10^{-2}\right)$, and inhibition of matrix metalloproteases $\left(P=1.53 \times 10^{-2}\right)$. Some of the top significantly enriched cellular functions were cell-to-cell signaling and interaction $\left(P=6.95 \times 10^{-5}\right)$, cellular assembly and organization $\left(P=6.95 \times 10^{-5}\right)$, cellular development $\left(P=1.39 \times 10^{-4}\right)$, cellular growth and proliferation $\left(P=1.39 \times 10^{-4}\right)$, cell death and survival $(P=4.8 \times$ $\left.10^{-4}\right)$, carbohydrate metabolism $\left(P=8.24 \times 10^{-4}\right)$, lipid metabolism $\left(P=2.34 \times 10^{-3}\right)$, nucleic acid metabolism $\left(P=4.84 \times 10^{-3}\right)$, amino acid metabolism $(P=9.67 \times$ $\left.10^{-3}\right)$, and energy production $\left(P=9.67 \times 10^{-3}\right)$ (Supplemental Figure S1B).

\section{Biological Processes Involved in Progression of SSA to SSA-HD}

Analysis of the 153 differentially expressed genes in SSA-HD compared with their nondysplastic counterparts found significant alterations in 47 key biological processes as defined by DAVID Bioinformatics and IPA. Thirty-eight of these biological processes were significantly up-regulated in SSA$\mathrm{HD}$, and nine processes were down-regulated (Figure 3B).

Enrichment of several canonical pathways were also highlighted by the analysis (Supplemental Figure S2A), such as axonal guidance signaling $\left(P=1.90 \times 10^{-3}\right)$; role of osteoblasts, osteoclasts, and chondrocytes in rheumatoid arthritis $\left(P=1.11 \times 10^{-3}\right) ; \mathrm{WNT} / \beta$-catenin signaling $(P=1.17 \times$ $\left.10^{-3}\right)$; VDR/RXR activation $\left(P=1.99 \times 10^{-2}\right)$; and inhibition of matrix metalloproteases $\left(P=2.34 \times 10^{-3}\right)$. Some of the top significantly enriched cellular functions were cell cycle $\left(P=1.60 \times 10^{-6}\right)$; cellular assembly and organization $\left(P=1.03 \times 10^{-5}\right) ;$ DNA replication, recombination, and 
A

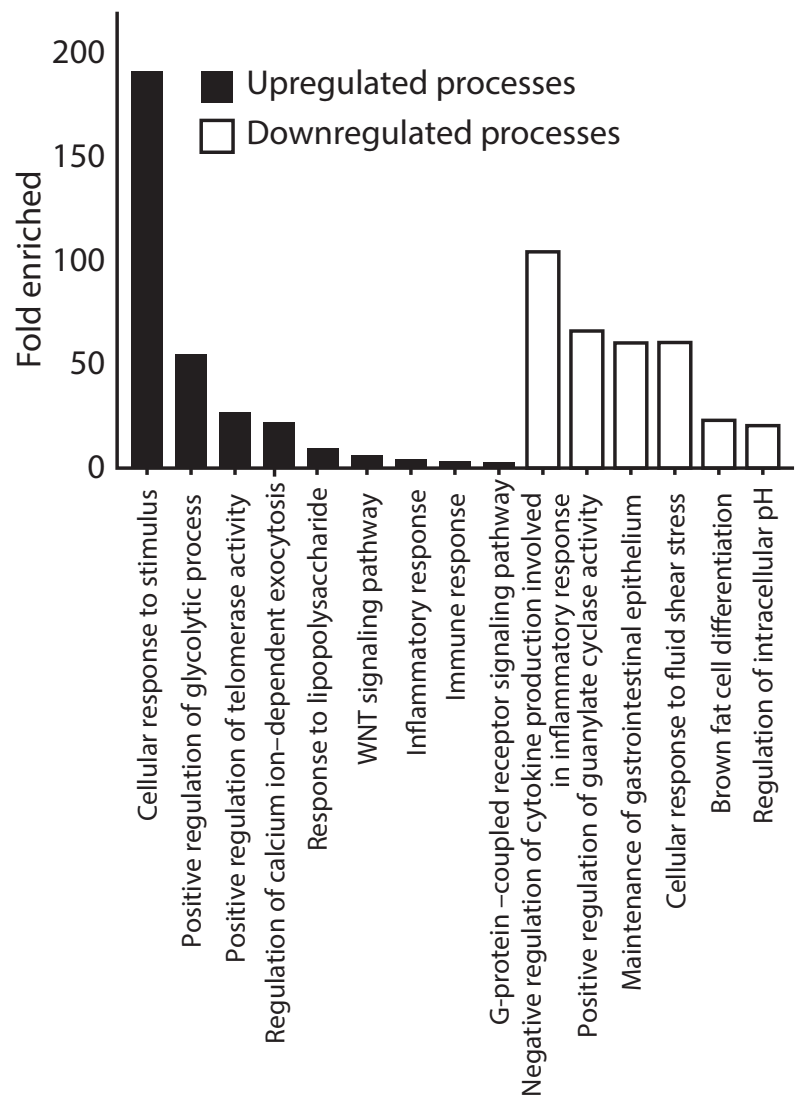

Figure 3 Gene ontology enrichment analysis of biological processes of the differentially expressed genes between sessile serrated adenoma-low grade $(\mathbf{A})$ or sessile serrated adenoma-high grade (B) and their nondysplastic counterparts. The biological processes were selected using false discovery rate $\leq 0.05$ in Database, Annotation, Visualization and Integrated Discovery (DAVID) software version 6.8.

B

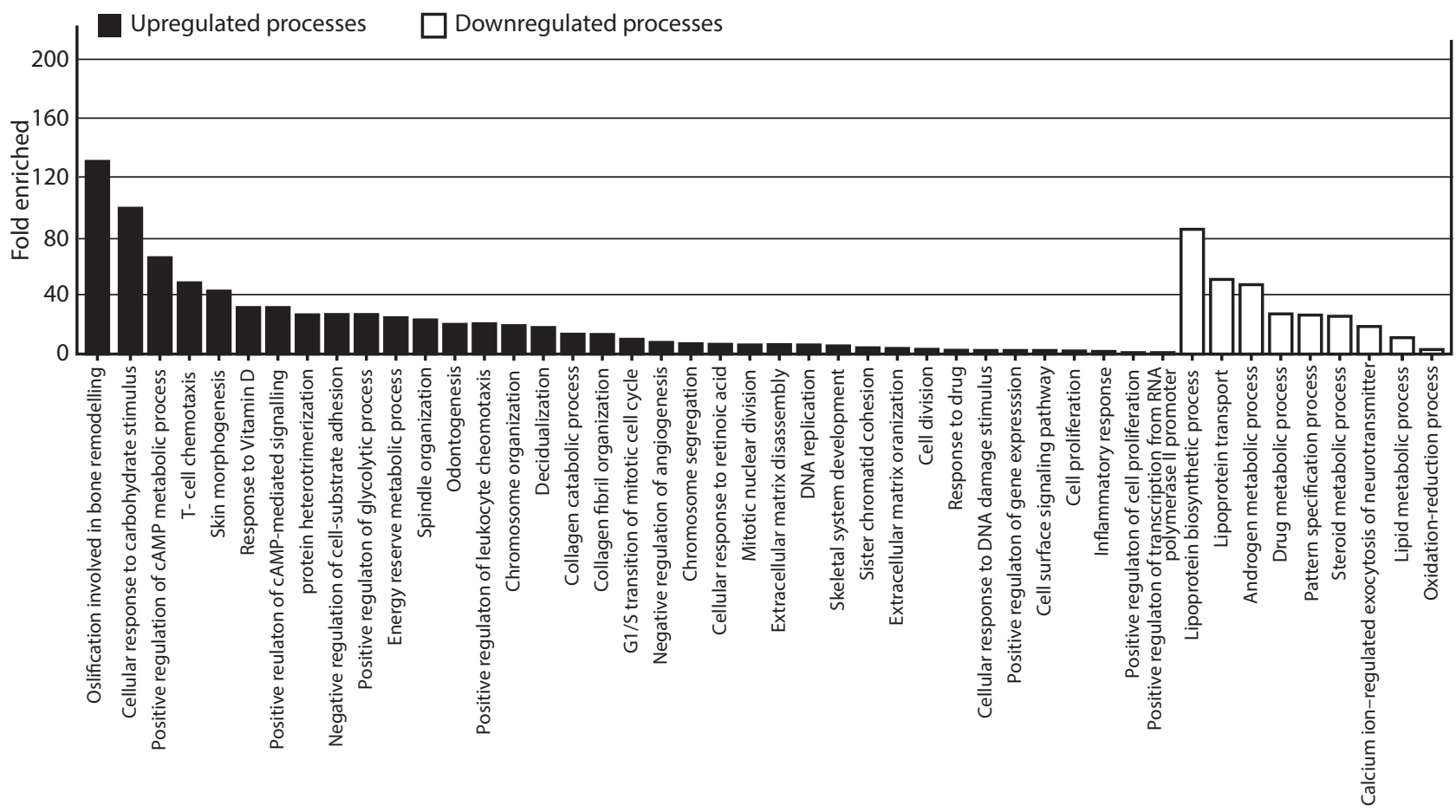



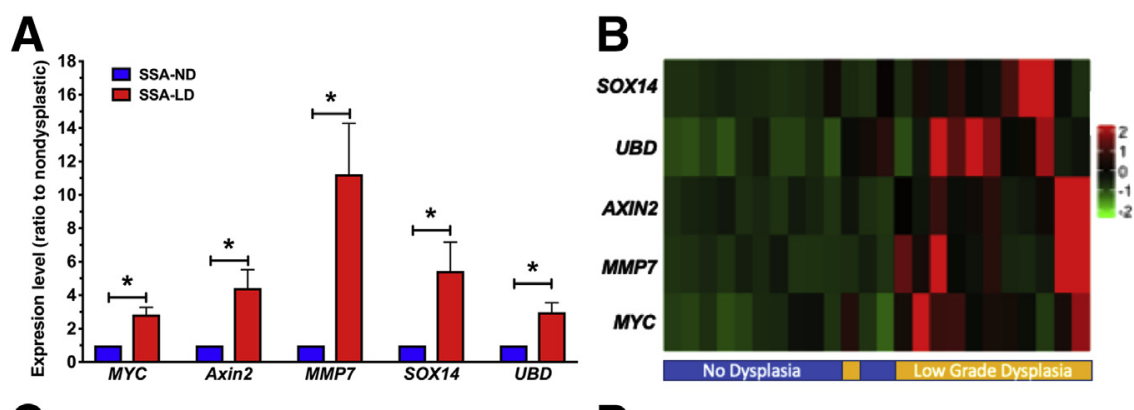

Figure 4 Relative expression levels of five differentially expressed genes (DEGs) involved in the WNT pathway in sessile serrated adenoma-low grade (SSA-LD) (A) and nonhierarchical clustering analysis of the same genes in SSA-LD (B) compared with no dysplasia (SSA-ND). Relative expression levels of six DEGs genes involved in the WNT pathway in sessile serrated adenoma-high grade (SSA-HD) (C) and nonhierarchical clustering analysis of the same genes in SSA-HD (D) compared with SSA-ND. ${ }^{*} P<0.05$.

repair $\left(P=1.03 . \times 10^{-5}\right)$; cell-to-cell signaling and interaction $\left(P=6.51 \times 10^{-5}\right)$; cellular growth and proliferation $\left(P=6.51 \times 10^{-5}\right)$; cell death and survival $\left(P=1.38 \times 10^{-4}\right)$; lipid metabolism $\left(P=1.38 \times 10^{-3}\right)$; protein synthesis $\left(P=3.24 \times 10^{-4}\right)$; carbohydrate metabolism $(P=7.67 \times$ $\left.10^{-4}\right)$; amino acid metabolism $\left(P=8.03 \times 10^{-4}\right)$; and nucleic acid metabolism $\left(P=9.46 \times 10^{-4}\right)$ (Supplemental Figure S2B).

\section{Activation of WNT/ $\beta$-Catenin Pathway in SSA-LD and SSA-HD Groups}

Analysis of the DEG by IPA software highlighted five genes involved in WNT pathway, which were overexpressed in the SSA-LD group compared with their nondysplastic counterparts. These genes were $M Y C, M M P 7, A X I N 2, U B D$, and SOX14 (Figure 4A). MYC, MMP7, and AXIN2 are known downstream gene targets of the WNT pathway. ${ }^{21}$ UBD is involved in the destruction process of $\beta$-catenin, ${ }^{21}$ and the mechanism of WNT pathway regulation by SOX14 is unknown. Unsupervised, nonhierarchical analysis of these five DEGs found that 11 of 12 SSA-LD samples were clustered into a distinct group separate from their SSA-ND counterparts (Figure 4B), which demonstrates that SSA-LD can generally be distinguished from their adjacent nondysplastic sample using expression analysis of these five genes.

Although the data indicate significant up-regulation of downstream effector genes involved in the WNT pathway, there is no evidence of involvement of more upstream WNT signaling genes (eg, WNT, FZD, LRP5/6 families of receptor, and $D V L$ ) in progression of SSA-ND to SSA-LD (Supplemental Figure S3, A-C). In addition, the expression levels of WNT pathway-mediated T-cell factor/ lymphoid enhancer-binding factor gene family are not affected (Supplemental Figure S3D). Among genes involved in the $\beta$-catenin destruction complex/pathway, two genes (AXIN2 and UBD) were up-regulated in SSA-LD compared with SSA-ND. No significant changes were identified in expression levels of AXIN1, APC, GSK-3, CSNK1, PP2A, and BTRC (Supplemental Figure S4).

In SSA-HD group, six genes involved in the WNT pathway were up-regulated compared with their SSA-ND matched samples, including the two downstream genes $M Y C$ and $M M P 7$, a WNT pathway ligand WNT2, UBD, SOX11, and TGFB3 (Figure 4C). Unsupervised, nonhierarchical analysis of these six DEGs in the SSA-HD group found that seven of nine SSA-HD samples were clustered into a distinct group separated from their SSA-ND counterparts (Figure 4D). This finding indicates that most SSA-HDs can be distinguished from their adjacent nondysplastic SSA by expression analysis of these six genes. These results confirm that the WNT pathway remains activated in SSA-HD. In addition, upregulation of $W N T 2$, a ligand known to drive the $\beta$-catenin signaling pathway, is particularly interesting because this phenomenon can explain the manner of WNT pathway activation in SSA-HD group.

To examine WNT pathway activation at the protein level, immunohistochemistry was used to evaluate nuclear $\beta$-catenin expression in a cohort of 20 dysplastic SSAs, including 10 SSA-LDs and 10 SSA-HDs. Positive nuclear $\beta$-catenin was found in 6 of 10 SSA-LDs (60\%) and 7 of 10 SSA-HDs (70\%). Background nondysplastic SSAs had only $10 \%(n=2 / 20)$ nuclear staining for $\beta$-catenin (Supplemental Figure S5). Immunohistochemistry revealed significantly higher nuclear $\beta$-catenin expression in SSA-LD $(P=0.003)$ and SSA-HD $(P=0.0007)$ compared with nondysplastic SSA. No difference in nuclear $\beta$-catenin expression was found between SSALD and SSA-HD $(P=0.63)$.

The analysis found up-regulation of AXIN2 in SSA-LDs but not SSA-HDs. Using methylation-specific PCR (MS-PCR), 


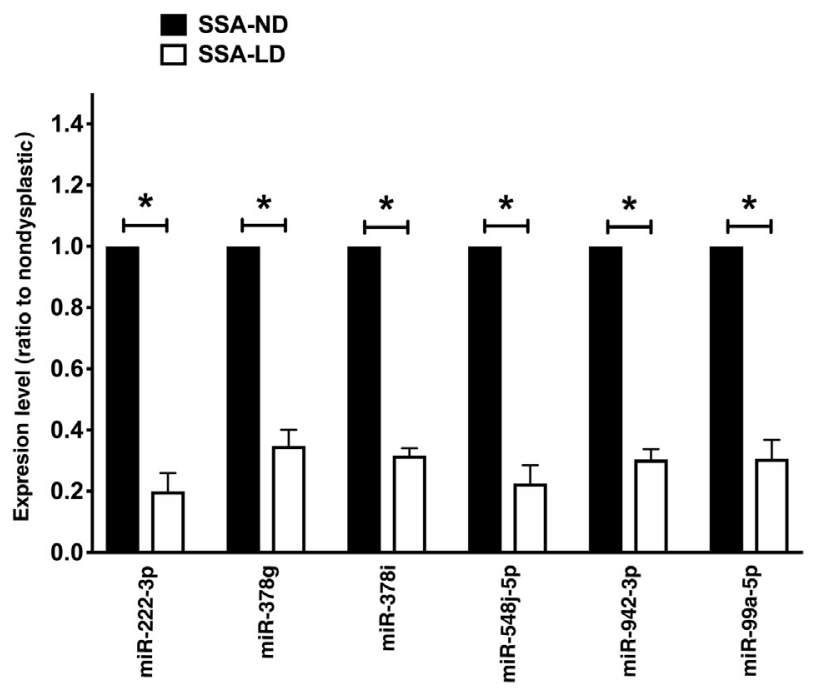

Figure 5 Relative expression levels of six miRNA down-regulated in sessile serrated adenoma-low grade (SSA-LD). Four SSA-LD polyps were selected, and the expression levels of 822 miRNA were evaluated and compared in dysplastic versus nondysplastic (SSA-ND) counterparts. ${ }^{*} P<0.05$.

methylation of AXIN2 was compared between SSA-LD and SSA-HD as a possible mechanism of AXIN2 regulation in this setting. Five randomly selected cases from each of SSA-LD and SSA-HD groups were included for MS-PCR. One case from each group failed amplification. Methylation of AXIN2 was detected in four of four SSA-LDs and three of four SSAHDs $(P=0.28)$ (Supplemental Figure S6).

\section{MicroRNA Expression Profile Highlights Down-}

Regulation of miR-222-3p in the SSA-LD Group with Specific Target mRNA AXIN2 in the WNT Pathway

To identify dysregulated miRNA and their mRNA targets in dysplastic SSAs, five SSA-LD polyps were randomly selected and miRNA expression levels in the dysplastic portion of the polyps were compared with those in the matched nondysplastic portion of each polyp, using NanoString platform. One sample failed to show optimal reads and was therefore excluded from the study. Two exclusion criteria were applied to reduce the large set of data: FDR $\leq 0.05$ and $\log _{2} \mathrm{FC}$ absolute value $>1.5$. From $822 \mathrm{miR}-$ NAs, which showed abundant expression levels, six miRNAs in the SSA-LD group were down-regulated compared with their nondysplastic counterparts (Figure 5). These miRNAs include miR-222-3p, miR-942-3p, miR-378g, miR-378i, miR-548j-5p, and mir-99a-5p. Many miRNAs were up-regulated in the SSA-LD group compared with the nondysplastic component, but the differential expressions were found to be insignificant after statistical analysis.

Next, the mRNA targets of these six down-regulated miRNAs were analyzed using IPA software. The IPA mRNA target library highlighted 323 target mRNAs involved in cancer pathogenesis for these six miRNAs. However, when the list of differentially expressed mRNA in the SSA-LD group was paired with these six downregulated miRNAs, only 14 mRNAs were matched. The list of these 14 mRNA is given in Table 1. From these 14 targeted mRNAs, only one, AXIN2, is known to be involved in the WNT/ $\beta$-catenin pathway, which is targeted by miR222-3p. To validate these findings, the expression level of miR-222-3p were examined in the rest of the SSA-LD cases that were not subjected to NanoString analysis. Quantitative RT-PCR studies found significantly decreased miR-222-3p in SSA-LDs compared with their nondysplastic counterparts $(P=0.033)$ (Supplemental Figure S7).

\section{Discussion}

In this study, a high-throughput and sensitive mRNA sequencing technology was used to compare the whole

Table 1 List of Five Down-Regulated miRNA with Their Paired Up-Regulated mRNA Targets in SSA Polyps with Areas of Low-Grade Dysplasia Group

\begin{tabular}{|c|c|c|c|c|c|}
\hline Down-regulated miRNA & Adjusted $P$ value & $\log _{2} \mathrm{FC}$ & Targeted mRNA & Adjusted $P$ value & $\log _{2} \mathrm{FC}$ \\
\hline $\operatorname{miR}-222-3 p$ & 0.0188 & -2.325 & $A Q P 3$ & 0.044 & 2.145 \\
\hline $\operatorname{miR}-222-3 p$ & 0.0188 & -2.325 & AXIN2 & 0.015 & 2.148 \\
\hline $\operatorname{miR}-222-3 p$ & 0.0188 & -2.325 & SYBU & 0.015 & 1.550 \\
\hline $\operatorname{miR}-942-3 p$ & 0.0260 & -1.72 & DSG3 & 0.044 & 1.742 \\
\hline $\operatorname{miR}-942-3 p$ & 0.0260 & -1.72 & KCNH8 & 0.015 & 1.676 \\
\hline $\operatorname{miR}-378 \mathrm{~g}$ & 0.0286 & -1.523 & $C B X 2$ & 0.025 & 2.359 \\
\hline $\operatorname{miR}-378 \mathrm{~g}$ & 0.0286 & -1.523 & ETV4 & 0.015 & 1.677 \\
\hline $\operatorname{miR}-378 \mathrm{~g}$ & 0.0286 & -1.523 & S100A2 & 0.017 & 1.641 \\
\hline miR-548j-5p & 0.0299 & -2.149 & $A Q P 3$ & 0.044 & 2.145 \\
\hline miR-548j-5p & 0.0299 & -2.149 & CXCL5 & 0.044 & 3.245 \\
\hline
\end{tabular}

The threshold set for a both miRNA and mRNA to be declaimed differentially expressed were false discovery rate $\leq 0.05$ and $\log _{2} \mathrm{FC}$ absolute value $>1.5$. $\mathrm{FC}$, fold change. 
transcriptome in dysplastic versus nondysplastic regions of each SSA polyp. To strengthen the study findings, the miRNA expression profile was also examined in parallel for a subset of polyps, and their mRNA targets were correlated with mRNA sequencing findings. This work aims to identify genes, biological processes, and signaling pathways that are involved in the progression of SSA-LD to SSA-HD. Two specific approaches were used to minimize the background genomic noise. First, by selecting SSA polyps only from the right side of the colon, the heterogeneity of SSA polyps known to be present between left- and right-sided SSAs was excluded. Second, by comparing dysplasia (low or high grade) to the adjacent nondysplastic area within the same polyp, the background genetic differences that might be present in polyps with similar stages of progression in different individuals or within one patient were minimized.

Numerous biological processes involved in rapid energy retrieval that were enriched in both the SSA-LD and SSAHD groups were identified. These processes include enhancement of cellular response to carbohydrate stimulus, glycolytic activity, regulation of cAMP metabolic processes, cAMP-mediated signaling, and energy reserve metabolic processes. In contrast, biological processes that are involved in more time-consuming energy retrieval or energyconsuming activities, such as oxidation-reduction reaction, lipoprotein transport, metabolism, biosynthetic processes, androgen and steroid metabolic processes, and brown fat cell differentiation, were reduced. These metabolic changes are all part of the well-known Warburg effect, which provides an immediate source of energy for rapidly growing neoplastic cells. In addition, multiple other biological processes were also enriched in both dysplastic groups, which are involved in enhancement of cell proliferation, including DNA replication, G1/S transition of mitotic cell cycle, chromosomal organization, chromosomal segregation, and mitotic nuclear division. Furthermore, in the SSA-LD group, positive regulation of telomerase activity was enriched, which is consistent with cell senescence, one of the well-known features of neoplasia. Apart from these changes, and specifically in the SSA-HD group, some other biological processes were enriched, which are involved in the enhancement of the ability of the neoplastic cells to invade. These processes include spindle cell organization, extracellular matrix disassembly, collagen catabolic process, collagen fibril organogenesis, and negative regulation of cell adhesion. All the above changes are a fundamental alteration in cell physiology, which is considered the hallmark of cancer.

Activation of WNT/ $\beta$-catenin pathways has an established role in conventional adenoma pathway mainly through $A P C$ and $C T N N B 1$ mutations. Recently, several studies have reported that activation of the WNT/ $\beta$-catenin pathway is involved in the development of dysplasia in SSA. ${ }^{22-24}$ Other studies failed to detect evidence of WNT/ $\beta$-catenin pathway activation in SSAs or sporadic MSI-H
CRCs arising from SSAs. ${ }^{25,26}$ The mechanism of WNT/ $\beta$ catenin activation in the serrated pathway has not been clearly elucidated. In contrast to the conventional adenoma pathway, mutations in the $A P C$ and $C T N N B 1$ genes are rare in the serrated pathway. ${ }^{22,24,27}$ Mutational analysis of the $A P C$ gene was not attempted in this study for two reasons: i) paucity of genomic material derived from targeted tissue and ii) mutational landscape of the $A P C$ gene in the serrated pathway has been extensively studied in the literature. More recent reports provided evidence of the presence of other mutations that affect the WNT pathway in the serrated pathway, including RNF43 mutation. RNF43 is a ubiquitin E3 ligase that down-regulates the WNT receptors, and therefore its inactivation up-regulates this pathway. ${ }^{28}$ Recently, it has been reported that a minor subset of SSAs have RNF43 mutations $^{29,30}$ and the RNF43 mutation was more frequently detected in SSAs with dysplasia compared with SSA. ${ }^{24}$ Our results support the activation of the WNT/ $\beta$-catenin signaling pathway in low- and high-grade dysplasia evidenced by overexpression of the downstream $\mathrm{B}$-catenin-targeted genes, including $C-M Y C, M M P 7$, and AXIN2. WNT/B-catenin activation is an early event because it was detected in low-grade dysplasia and likely is required for maintaining neoplastic potential because it continues to be present in the high-grade dysplasia stage. Immunohistochemistry using $\beta$-catenin antibody in a small cohort of dysplastic SSAs confirmed WNT/ $\beta$-catenin activation in both SSA-LDs and SSA-HDs. No changes were observed in the expression levels of $A P C, C T N N B 1$, or RNF43. However, this study cannot rule out the possibility of RNF43 involvement in the progression of SSA through loss of function mutations (without expression loss). Interestingly, this study highlighted another potential mechanism for activation of WNT/ $\beta$-catenin pathway in SSA-HD through up-regulation of WNT2. WNT2 is a member of the WNT family previously reported to activate the canonical WNT/ $\beta$ catenin pathway in the conventional CRC pathway. The mechanism of WNT2 up-regulation is not clear. ${ }^{31}$ However, recent studies suggest a role for stromal fibroblasts in WNT2 up-regulation in conventional adenoma-carcinoma sequence. $^{32}$ Therefore, it is plausible that stromal fibroblasts in the setting of dysplastic SSA activate the WNT/ $\beta$-catenin pathway in neoplastic epithelial cells through paracrine secretion of WNT2.

A significant positive trend in the expression of metalloproteinase MMP7 from SSA-LD to SSA-HD was noted in our experiment. An overexpression of MMP7 has been reported as a prognostic marker, and its increased expression or serum level is linked to metastatic disease. ${ }^{33-36}$ These results are in line with those reported by Polistena et $\mathrm{al}^{37}$ in which a positive trend in the expression of MMP7 was found in the conventional adenoma-carcinoma pathway. This finding is believed to be one of the alterations in the neoplastic process to acquire the ability of invasion. The role of $M M P 7$ in serrated CRC has not been investigated in detail; however, its overexpression has been reported in 
MSI-H CRC through WNT/B-catenin signaling as a marker of activation of this pathway. ${ }^{38}$

Unpaired comparison between the SSA-LD and SSA-HD groups revealed three genes with significant differential expression, namely LGALS1 (which express galectin-1), Spockl, and TGFB2. LGALS1 is involved in cell adhesions, interaction with extracellular matrix, migration, angiogenesis, and metastasis. The role of LGALSlin progression and metastasis of CRC is documented in the literature. ${ }^{39-41}$ Spockl is involved in proliferation, adhesion, and cell-matrix interaction. Overexpression of Spock1 in CRC is also documented in the literature. ${ }^{42,43}$

There is now emerging evidence to suggest that alterations in the expression of small noncoding RNA genes, including miRNA, can also lead to carcinogenesis. The role of microRNA-mRNA interactions in CRC progression has been described in great detail elsewhere. ${ }^{44}$ To our knowledge, no prior study compared the miRNA expression profile between SSA without dysplasia and SSA with dysplasia. miRNA evaluation was performed on the same lysates from paired samples of SSA and morphologic dysplasia that were sent for mRNA sequencing. With the use of stringent criteria, differentially expressed miRNAs were determined and their targeted mRNAs were compared with the data from mRNA expression profiling. Fourteen mRNAs were found to be common targets in both miRNA and mRNA data. The involvement of most of these genes, including $A Q p 3, R A B 15$, DSG3, KCNH8, RNF183, APLN, CBX2, S100A2, CXCL5, and SRCIN 1 in development and/or progression of CRC, has been documented in the literature. ${ }^{45-55}$ Among these targets, the association of miR-222-3p and enhanced expression of its target AXIN 2 is specifically interesting. AXINs are the scaffolding proteins that are required for the formation of $\beta$-catenin destruction complex. Their function reduces the $\beta$-catenin bioavailability and consequently negatively affects the WNT/ $\beta$-catenin signaling pathway. ${ }^{56}$ Therefore, their overexpression argues against the WNT pathway activity. However, AXIN2 is a well-characterized target of WNT signaling and is expressed in a WNT/ $\beta$-catenin signaling-dependent manner as part of a negative feedback loop to control the WNT/ $\beta$-catenin signaling. ${ }^{57}$ Therefore, up-regulation of AXIN2 indeed is a hallmark of WNT/ $\beta$-catenin pathway activation. The overexpression of AXIN2 has been previously reported in various tumors, including CRC. ${ }^{58}$ Genome-scale exome sequencing analysis conducted by the Cancer Genome Atlas Project has reported that in MSI-H colon cancers AXIN2 has altered through WNT/B-catenin signaling. ${ }^{38}$ However, in this study, despite AXIN2 upregulation in SSA-LD, this alteration was absent in the SSA-HD group. It has recently been reported that AXIN2 is silenced in MSI-H CRC. It has been argued that the methylation as part of the CIMP phenotype can extend into the promoter region of $A X I N 2$, leading to the gradual suppression of the AXIN2 gene expression, which contributes to a stepwise acquisition of the epigenetic features seen in sporadic MSI-H colon cancer. ${ }^{20}$ In addition, Murakami et $\mathrm{al}^{23}$ found a stepwise increment of $A X I N 2$ methylation with progression to high-grade dysplasia and submucosal carcinoma, resulting in silencing of AXIN2 in MSI-H CRC. AXIN2 methylation was compared by MS-PCR using lysates of five SSA-LDs and five SSA-HDs. There was no significant difference in the number of cases with methylated AXIN2 between the two groups. However, MS-PCR is a semiquantitative method for analysis of methylation; therefore, the difference in methylation as a cause of AXIN2 expression cannot be completely excluded.

In this study, the whole genome transcriptome as well as miRNAs in SSA with dysplasia were compared with their nondysplastic counterparts. The unique approach, discussed above, has reduced the background noise from genetic variations. Different genes, pathways, and biological processes involved in the initiation and progression of dysplasia were documented. The results confirmed that the WNT/ $\beta$ catenin pathway is activated in the early stage of dysplasia (ie, low-grade dysplasia) in the serrated pathway of tumorigenesis. WNT2 and AXIN2 were identified as markers of the WNT/ $\beta$-catenin pathway activation in the serrated pathway, and for the first time, five miRNA and their mRNA targets that are differentially expressed in SSA-LD compared with their nondysplastic counterparts have been introduced.

\section{Acknowledgments}

We thank Dr. Jennifer Chan, Carles Vilarino-Guell, John McIntire, Shuhong Liu, Young Ou, and Xiuling Wang for technical support; and Thomas Kryton for his help in preparation of figures.

M.N. wrote the manuscript, analyzed the data, and prepared the figures and tables; A.M. and Q.Z. analyzed the data and prepared the figures; K.K. analyzed miRNA data; P.M. conceived the ideas, analyzed the data, and wrote the manuscript; P.M. is the guarantor of this work and, as such, had full access to all the data in the study and takes responsibility for the integrity of the data and the accuracy of the data analysis.

\section{Supplemental Data}

Supplemental material for this article can be found at http://doi.org/10.1016/j.ajpath.2019.05.009.

\section{References}

1. Ferlay J, Soerjomataram I, Dikshit R, Eser S, Mathers C, Rebelo M, Parkin DM, Forman D, Bray F: Cancer incidence and mortality worldwide: sources, methods and major patterns in GLOBOCAN 2012. Int J Cancer 2015, 136:E359-E386

2. Bettington $\mathrm{M}$, Walker $\mathrm{N}$, Clouston A, Brown I, Leggett B, Whitehall V: The serrated pathway to colorectal carcinoma: current concepts and challenges. Histopathology 2013, 62:367-386

3. Rex DK, Ahnen DJ, Baron JA, Batts KP, Burke CA, Burt RW, Goldblum JR, Guillem JG, Kahi CJ, Kalady MF, O'Brien MJ, Odze RD, Ogino S, Parry S, Snover DC, Torlakovic EE, Wise PE, Young J, Church J: Serrated lesions of the colorectum: review and 
recommendations from an expert panel. Am J Gastroenterol 2012, 107:1315-1329. quiz 4, 30

4. Higuchi T, Jass JR: My approach to serrated polyps of the colorectum. J Clin Pathol 2004, 57:682-686

5. Issa JP: CpG island methylator phenotype in cancer. Nat Rev Cancer 2004, 4:988-993

6. Jass JR: Serrated adenoma of the colorectum and the DNAmethylator phenotype. Nat Clin Pract Oncol 2005, 2:398-405

7. Park SJ, Rashid A, Lee JH, Kim SG, Hamilton SR, Wu TT: Frequent $\mathrm{CpG}$ island methylation in serrated adenomas of the colorectum. Am J Pathol 2003, 162:815-822

8. Phipps AI, Limburg PJ, Baron JA, Burnett-Hartman AN, Weisenberger DJ, Laird PW, Sinicrope FA, Rosty C, Buchanan DD, Potter JD, Newcomb PA: Association between molecular subtypes of colorectal cancer and patient survival. Gastroenterology 2015, 148: 77-87.e2

9. Hawkins N, Norrie M, Cheong K, Mokany E, Ku SL, Meagher A, O'Connor T, Ward R: CpG island methylation in sporadic colorectal cancers and its relationship to microsatellite instability. Gastroenterology 2002, 122:1376-1387

10. Whitehall VL, Wynter CV, Walsh MD, Simms LA, Purdie D, Pandeya N, Young J, Meltzer SJ, Leggett BA, Jass JR: Morphological and molecular heterogeneity within nonmicrosatellite instabilityhigh colorectal cancer. Cancer Res 2002, 62:6011-6014

11. Yamamoto E, Suzuki H, Yamano HO, Maruyama R, Nojima M, Kamimae S, Sawada T, Ashida M, Yoshikawa K, Kimura T, Takagi R, Harada T, Suzuki R, Sato A, Kai M, Sasaki Y, Tokino T, Sugai T, Imai K, Shinomura Y, Toyota M: Molecular dissection of premalignant colorectal lesions reveals early onset of the $\mathrm{CpG}$ island methylator phenotype. Am J Pathol 2012, 181:1847-1861

12. Li W, Turner A, Aggarwal P, Matter A, Storvick E, Arnett DK, Broeckel U: Comprehensive evaluation of AmpliSeq transcriptome, a novel targeted whole transcriptome RNA sequencing methodology for global gene expression analysis. BMC Genomics 2015, 16:1069

13. Zhang JD, Schindler T, Kung E, Ebeling M, Certa U: Highly sensitive amplicon-based transcript quantification by semiconductor sequencing. BMC Genomics 2014, 15:565

14. Tyekucheva S, Martin NE, Stack EC, Wei W, Vathipadiekal V, Waldron L, Fiorentino M, Lis RT, Stampfer MJ, Loda M, Parmigiani G, Mucci LA, Birrer M: Comparing platforms for messenger RNA expression profiling of archival formalin-fixed, paraffin-embedded tissues. J Mol Diagn 2015, 17:374-381

15. Scott DW, Wright GW, Williams PM, Lih CJ, Walsh W, Jaffe ES, Rosenwald A, Campo E, Chan WC, Connors JM, Smeland EB, Mottok A, Braziel RM, Ott G, Delabie J, Tubbs RR, Cook JR, Weisenburger DD, Greiner TC, Glinsmann-Gibson BJ, Fu K, Staudt LM, Gascoyne RD, Rimsza LM: Determining cell-of-origin subtypes of diffuse large B-cell lymphoma using gene expression in formalin-fixed paraffin-embedded tissue. Blood 2014, 123:1214-1217

16. Guinney J, Dienstmann R, Wang X, de Reynies A, Schlicker A, Soneson C, et al: The consensus molecular subtypes of colorectal cancer. Nat Med 2015, 21:1350-1356

17. Delker DA, McGettigan BM, Kanth P, Pop S, Neklason DW, Bronner MP, Burt RW, Hagedorn CH: RNA sequencing of sessile serrated colon polyps identifies differentially expressed genes and immunohistochemical markers. PLoS One 2014, 9:e88367

18. Kim K, Park U, Wang J, Lee J, Park S, Kim S, Choi D, Kim C, Park J: Gene profiling of colonic serrated adenomas by using oligonucleotide microarray. Int J Colorectal Dis 2008, 23:569-580

19. Sha Y, Phan JH, Wang MD: Effect of low-expression gene filtering on detection of differentially expressed genes in RNA-seq data. Conf Proc IEEE Eng Med Biol Soc 2015, 2015:6461-6464

20. Muto Y, Maeda T, Suzuki K, Kato T, Watanabe F, Kamiyama H, Saito M, Koizumi K, Miyaki Y, Konishi F, Alonso S, Perucho M, Rikiyama T: DNA methylation alterations of AXIN2 in serrated adenomas and colon carcinomas with microsatellite instability. BMC Cancer 2014, 14:466
21. Clevers H, Nusse R: Wnt/beta-catenin signaling and disease. Cell 2012, 149:1192-1205

22. Yachida S, Mudali S, Martin SA, Montgomery EA, IacobuzioDonahue CA: Beta-catenin nuclear labeling is a common feature of sessile serrated adenomas and correlates with early neoplastic progression after BRAF activation. Am J Surg Pathol 2009, 33: $1823-1832$

23. Murakami T, Mitomi H, Saito T, Takahashi M, Sakamoto N, Fukui N, Yao T, Watanabe S: Distinct WNT/beta-catenin signaling activation in the serrated neoplasia pathway and the adenomacarcinoma sequence of the colorectum. Mod Pathol 2015, 28: $146-158$

24. Hashimoto T, Yamashita S, Yoshida H, Taniguchi H, Ushijima T, Yamada T, Saito Y, Ochiai A, Sekine S, Hiraoka N: WNT pathway gene mutations are associated with the presence of dysplasia in colorectal sessile serrated adenoma/polyps. Am J Surg Pathol 2017, $41: 1188-1197$

25. Yamamoto T, Konishi K, Yamochi T, Makino R, Kaneko K, Shimamura T, Ota H, Mitamura K: No major tumorigenic role for beta-catenin in serrated as opposed to conventional colorectal adenomas. Br J Cancer 2003, 89:152-157

26. Panarelli NC, Vaughn CP, Samowitz WS, Yantiss RK: Sporadic microsatellite instability-high colon cancers rarely display immunohistochemical evidence of Wnt signaling activation. Am J Surg Pathol 2015, 39:313-317

27. Borowsky J, Dumenil T, Bettington M, Pearson SA, Bond C, Fennell L, Liu C, McKeone D, Rosty C, Brown I, Walker N, Leggett B, Whitehall V: The role of APC in WNT pathway activation in serrated neoplasia. Mod Pathol 2018, 31:495-504

28. Koo BK, Spit M, Jordens I, Low TY, Stange DE, van de Wetering M, van Es JH, Mohammed S, Heck AJ, Maurice MM, Clevers H: Tumour suppressor RNF43 is a stem-cell E3 ligase that induces endocytosis of Wnt receptors. Nature 2012, 488:665-669

29. Tsai JH, Liau JY, Yuan CT, Lin YL, Tseng LH, Cheng ML, Jeng YM: RNF43 is an early and specific mutated gene in the serrated pathway, with increased frequency in traditional serrated adenoma and its associated malignancy. Am J Surg Pathol 2016, 40: $1352-1359$

30. Yan HHN, Lai JCW, Ho SL, Leung WK, Law WL, Lee JFY, Chan AKW, Tsui WY, Chan ASY, Lee BCH, Yue SSK, Man AHY, Clevers H, Yuen ST, Leung SY: RNF43 germline and somatic mutation in serrated neoplasia pathway and its association with BRAF mutation. Gut 2017, 66:1645-1656

31. Jung YS, Jun S, Lee SH, Sharma A, Park JI: Wnt2 complements Wnt/ $\beta$-catenin signaling in colorectal cancer. Oncotarget 2015, 6: 37257-37268

32. Kramer N, Schmollerl J, Unger C, Nivarthi H, Rudisch A, Unterleuthner D, Scherzer M, Riedl A, Artaker M, Crncec I, Lenhardt D, Schwarz T, Prieler B, Han X, Hengstschlager M, Schuler J, Eferl R, Moriggl R, Sommergruber W, Dolznig H: Autocrine WNT2 signaling in fibroblasts promotes colorectal cancer progression. Oncogene 2017, 36:5460-5472

33. DeClerck YA, Perez N, Shimada H, Boone TC, Langley KE, Taylor SM: Inhibition of invasion and metastasis in cells transfected with an inhibitor of metalloproteinases. Cancer Res 1992, 52: 701-708

34. Mori M, Barnard GF, Mimori K, Ueo H, Akiyoshi T, Sugimachi K: Overexpression of matrix metalloproteinase-7 mRNA in human colon carcinomas. Cancer 1995, 75:1516-1519

35. Ichikawa Y, Ishikawa T, Momiyama N, Yamaguchi S, Masui H, Hasegawa S, Chishima T, Takimoto A, Kitamura H, Akitaya T, Hosokawa T, Mitsuhashi M, Shimada H: Detection of regional lymph node metastases in colon cancer by using RT-PCR for matrix metalloproteinase 7, matrilysin. Clin Exp Metastasis 1998, $16: 3-8$

36. Lloyd JM, McIver CM, Stephenson SA, Hewett PJ, Rieger N, Hardingham JE: Identification of early-stage colorectal cancer 
patients at risk of relapse post-resection by immunobead reverse transcription-PCR analysis of peritoneal lavage fluid for malignant cells. Clin Cancer Res 2006, 12:417-423

37. Polistena A, Cucina A, Dinicola S, Stene C, Cavallaro G, Ciardi A, Orlando G, Arena R, D'Ermo G, Cavallaro A, Johnson LB, De Toma G: MMP7 expression in colorectal tumours of different stages. In Vivo 2014, 28:105-110

38. Albuquerque C, Baltazar C, Filipe B, Penha F, Pereira T, Smits R, Cravo M, Lage P, Fidalgo P, Claro I, Rodrigues P, Veiga I, Ramos JS, Fonseca I, Leitao CN, Fodde R: Colorectal cancers show distinct mutation spectra in members of the canonical WNT signaling pathway according to their anatomical location and type of genetic instability. Genes Chromosomes Cancer 2010, 49:746-759

39. Wu Y, Liu M, Li Z, Wu XB, Wang Y, Wang Y, Nie M, Huang F, Ju J, Ma C, Tan R, Zen K, Zhang CY, Fu K, Chen YG, Wang MR, Zhao Q: LYAR promotes colorectal cancer cell mobility by activating galectin-1 expression. Oncotarget 2015, 6:32890-32901

40. Hittelet A, Legendre H, Nagy N, Bronckart Y, Pector JC, Salmon I, Yeaton P, Gabius HJ, Kiss R, Camby I: Upregulation of galectins-1 and -3 in human colon cancer and their role in regulating cell migration. Int J Cancer 2003, 103:370-379

41. Barrow H, Rhodes JM, Yu LG: The role of galectins in colorectal cancer progression. Int J Cancer 2011, 129:1-8

42. Zhao P, Guan HT, Dai ZJ, Ma YG, Liu XX, Wang XJ: Knockdown of SPOCK1 inhibits the proliferation and invasion in colorectal cancer cells by suppressing the PI3K/Akt pathway. Oncol Res 2016, 24:437-445

43. Zhang J, Zhi X, Shi S, Tao R, Chen P, Sun S, Bian L, Xu Z, Ma L: SPOCK1 is up-regulated and promotes tumor growth via the $\mathrm{PI} 3 \mathrm{~K} / \mathrm{AKT}$ signaling pathway in colorectal cancer. Biochem Biophys Res Commun 2017, 482:870-876

44. Guo Y, Bao Y, Yang W: Regulatory miRNAs in colorectal carcinogenesis and metastasis. Int J Mol Sci 2017, 18

45. Kang BW, Kim JG, Lee SJ, Chae YS, Jeong JY, Yoon GS, Park SY, Kim HJ, Park JS, Choi GS, Jeong JY: Expression of aquaporin-1, aquaporin-3, and aquaporin-5 correlates with nodal metastasis in colon cancer. Oncology 2015, 88:369-376

46. Guo Y, Bao Y, Ma M, Yang W: Identification of key candidate genes and pathways in colorectal cancer by integrated bioinformatical analysis. Int J Mol Sci 2017, 18:722

47. Bujko M, Kober P, Mikula M, Ligaj M, Ostrowski J, Siedlecki JA: Expression changes of cell-cell adhesion-related genes in colorectal tumors. Oncol Lett 2015, 9:2463-2470
48. Pagnotta SM, Laudanna C, Pancione M, Sabatino L, Votino C, Remo A, Cerulo L, Zoppoli P, Manfrin E, Colantuoni V, Ceccarelli M: Ensemble of gene signatures identifies novel biomarkers in colorectal cancer activated through PPARgamma and TNFalpha signaling. PLoS One 2013, 8:e72638

49. Geng R, Tan X, Wu J, Pan Z, Yi M, Shi W, Liu R, Yao C, Wang G, Lin J, Qiu L, Huang W, Chen S: RNF183 promotes proliferation and metastasis of colorectal cancer cells via activation of NF-kappaB-IL-8 axis. Cell Death Dis 2017, 8:e2994

50. Picault FX, Chaves-Almagro C, Projetti F, Prats H, Masri B, Audigier Y: Tumour co-expression of apelin and its receptor is the basis of an autocrine loop involved in the growth of colon adenocarcinomas. Eur J Cancer 2014, 50:663-674

51. Clermont PL, Sun L, Crea F, Thu KL, Zhang A, Parolia A, Lam WL, Helgason CD: Genotranscriptomic meta-analysis of the Polycomb gene CBX2 in human cancers: initial evidence of an oncogenic role. Br J Cancer 2014, 111:1663-1672

52. Masuda T, Ishikawa T, Mogushi K, Okazaki S, Ishiguro M, Iida S, Mizushima H, Tanaka H, Uetake H, Sugihara K: Overexpression of the S100A2 protein as a prognostic marker for patients with stage II and III colorectal cancer. Int J Oncol 2016, 48:975-982

53. Alajez NM: Large-scale analysis of gene expression data reveals a novel gene expression signature associated with colorectal cancer distant recurrence. PLoS One 2016, 11:e0167455

54. Zhao J, Ou B, Han D, Wang P, Zong Y, Zhu C, Liu D, Zheng M, Sun J, Feng H, Lu A: Tumor-derived CXCL5 promotes human colorectal cancer metastasis through activation of the ERK/Elk1/Snail and AKT/GSK3beta/beta-catenin pathways. Mol Cancer $2017,16: 70$

55. Zhang M, Ma F, Xie R, Wu Y, Wu M, Zhang P, Peng Y, Zhao J, Xiong J, Li A, Kequan C, Zhang Y, Liu S, Wang J, Chen X: Overexpression of Srcin 1 contributes to the growth and metastasis of colorectal cancer. Int J Oncol 2017, 50:1555-1566

56. Chia IV, Costantini F: Mouse axin and axin2/conductin proteins are functionally equivalent in vivo. Mol Cell Biol 2005, 25:4371-4376

57. Jho EH, Zhang T, Domon C, Joo CK, Freund JN, Costantini F: Wnt/beta-catenin/Tcf signaling induces the transcription of Axin2, a negative regulator of the signaling pathway. Mol Cell Biol 2002, 22: $1172-1183$

58. Schaal U, Grenz S, Merkel S, Rau TT, Hadjihannas MV, Kremmer E, Chudasama P, Croner RS, Behrens J, Sturzl M, Naschberger E: Expression and localization of axin 2 in colorectal carcinoma and its clinical implication. Int J Colorectal Dis 2013, 28:1469-1478 